\title{
Acute immune thrombocytopenia following SARS-CoV-2 vaccination in chronic ITP patients and a healthy individual
}

\author{
Asuka Ogai ${ }^{1,2} \cdot$ Ryuto Yoshida $^{2} \cdot$ Chiaki Yuasa $^{2} \cdot$ Kenko Chin $^{1} \cdot$ Katsumichi Fujimaki $^{3} \cdot$ Hideaki Nakajima $^{1,4}([)$
}

Received: 17 September 2021 / Revised: 6 October 2021 / Accepted: 6 October 2021 / Published online: 30 October 2021

(c) Japanese Society of Hematology 2021

\section{Dear Editor,}

As the vaccination program for COVID-19 progresses worldwide, rare but significant adverse events associated with vaccination are becoming a global concern. In the field of hematology, exacerbation of idiopathic thrombocytopenic purpura (ITP) or acute-onset immune thrombocytopenia occurring shortly after vaccination is attracting attention $[1$, 2]. Kuter et al. reported that exacerbation of ITP is observed at a significantly higher rate than would be expected, even among patients in remission with normal platelet counts [2]. However, the precise nature, incidence and appropriate management of immune thrombocytopenia after SARS-CoV-2 vaccination remains unclear. We herein report three cases of severe and acute immune thrombocytopenia following SARS-CoV-2 vaccination in two patients with chronic ITP in remission and in one healthy individual.

Case 1 was a 64-year-old woman with chronic ITP managed without medication for 23 years. Her platelet count had been stable around $40 \times 10^{9} / \mathrm{L}$. She visited our hospital complaining of oral mucosal bleeding and petechiae on the extremities. Two days before the visit, she received the first dose of the BNT162b2 mRNA covid-19 vaccine (Comirnaty, Pfizer) for SARS-CoV-2 (Fig. 1A). She did not take any medication or supplements before or after vaccination. Oral bleeding and generalized petechiae were observed on physical examination. Laboratory testing showed severe

Hideaki Nakajima

hnakajim@yokohama-cu.ac.jp

1 Department of Hematology, Keiyu Hospital, Yokohama, Japan

2 Department of Medicine, Keiyu Hospital, Yokohama, Japan

3 Department of Hematology, Fujisawa City Hospital, Fujisawa, Japan

4 Department of Hematology and Clinical Immunology, Yokohama City University School of Medicine, 3-9 Fuku-ura, Kanazawa-ku, Yokohama 236-0004, Japan thrombocytopenia with $1 \times 10^{9} / \mathrm{L}$ platelets, while white blood cells (WBCs), red blood cells (RBCs) and hemoglobin $(\mathrm{Hb})$ levels were within normal limits (Fig. 1A). The international normalized ratio of prothrombin time (PT-INR), activated partial thromboplastin time (APTT), fibrinogen, fibrin/fibrinogen degradation products (FDP), D-dimer and all blood chemistry parameters were within normal range. Clinical and laboratory findings were consistent with acute exacerbation of ITP, and thus treatment with oral prednisolone (PSL) $55 \mathrm{mg} / \mathrm{day}(1 \mathrm{mg} / \mathrm{kg})$ and intravenous immunoglobulin (IVIG) $20 \mathrm{~g} /$ day for 5 days was started. Complete blood cell (CBC) count after two days of treatment showed effective platelet recovery to $76 \times 10^{9} / \mathrm{L}$ (Fig. 1A). The patient had been in good physical condition and cutaneous purpura progressively improved. CBC after 5 days of PSL treatment showed a normal platelet count of $274 \times 10^{9} / \mathrm{L}$.

Case 2 was a 61-year-old woman with scleroderma (SSc), Sjogren syndrome (SS) and ITP who presented with petechiae on both legs after the second dose of SARSCoV-2 vaccine. SSc and SS had been clinically stable without medication for 34 years. Eleven months earlier, she was diagnosed with ITP due to acute-onset thrombocytopenia with $1 \times 10^{9} / \mathrm{L}$ platelets and with widespread petechiae on extremities. Her platelet count and bleeding symptoms had effectively improved with PSL, which had been gradually tapered and discontinued 6 months prior to presentation. She had received the first and second doses of BNT162b2 mRNA covid-19 vaccine (Pfizer) 42 days and 21 days prior to the visit, respectively (Fig. 1B). She noticed subcutaneous bleeding 17 days after the second vaccination and visited the hospital 21 days after the second vaccination. Diffuse petechiae on the legs with no active bleeding were observed on physical examination. Laboratory tests showed severe thrombocytopenia with a platelet count of $1 \times 10^{9} / \mathrm{L}$, but other CBC parameters, coagulation parameters including PT-INR, APTT, fibrinogen, FDP and D-dimer, and blood chemistry parameters were otherwise normal (Fig. 1B). Based on these findings, 
a

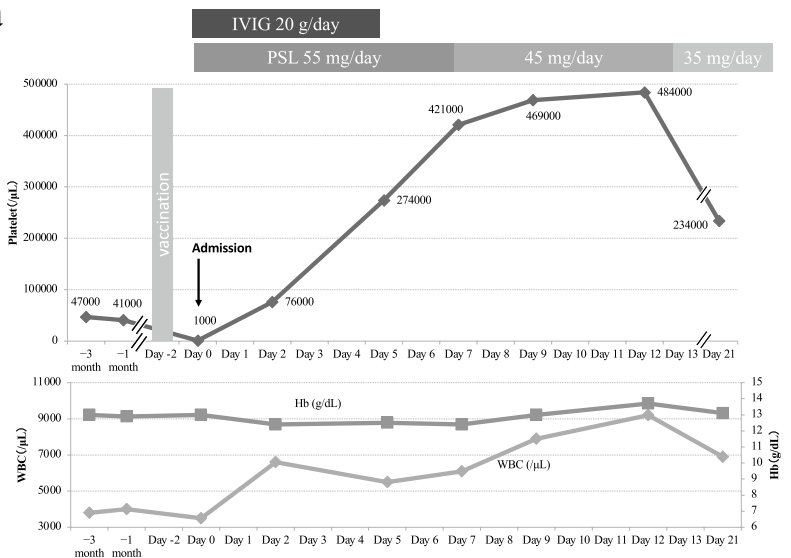

b

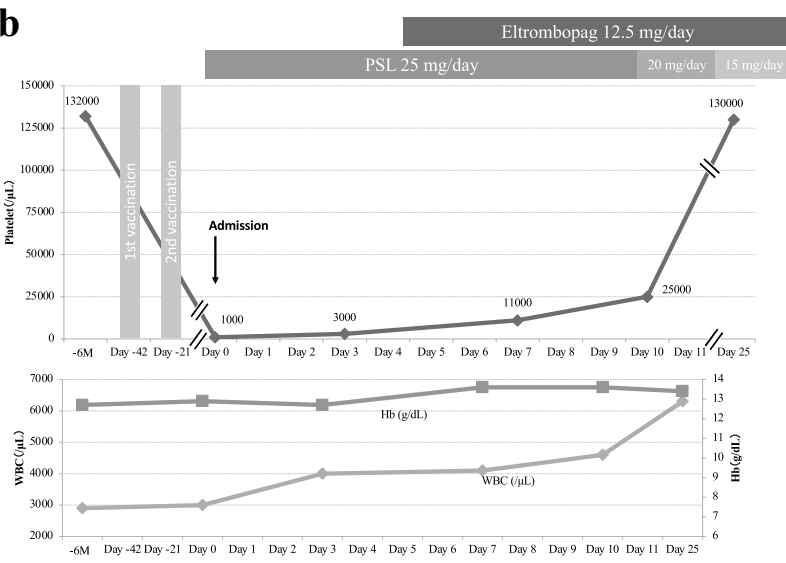

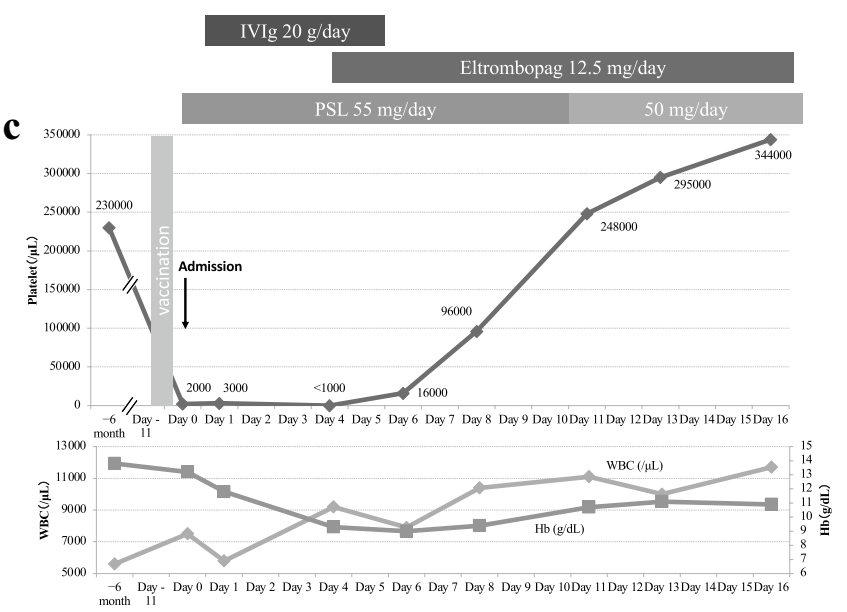

d

\begin{tabular}{|c|c|c|c|c|c|c|c|c|c|c|}
\hline $\begin{array}{l}\text { Case } \\
\text { number }\end{array}$ & Age & Gender & $\begin{array}{l}\text { Duration of } \\
\text { ITP }\end{array}$ & $\begin{array}{l}\text { Active } \\
\text { treatment } \\
\text { for ITP }\end{array}$ & $\begin{array}{l}\text { PLT count } \\
\text { prior to } \\
\text { vaccination } \\
\left(\times 10^{9} / \mathrm{L}\right)\end{array}$ & $\begin{array}{l}\text { Vaccination } \\
\text { type }\end{array}$ & $\begin{array}{c}\text { Lowest } \\
\text { PLT count } \\
\text { post } \\
\text { vaccination } \\
\left(\times 10^{9} / \mathrm{L}\right)\end{array}$ & $\begin{array}{l}\text { Onset of } \\
\text { thrombocytopenia/ } \\
\text { bleeding symptoms } \\
\text { after vaccination }\end{array}$ & Treatment & $\begin{array}{c}\text { Days until PLT } \\
>30 \times 10^{9} / \mathrm{L}\end{array}$ \\
\hline 1 & 64 & Female & 23 years & No & 47 & Pfizer & 1.0 & $\begin{array}{l}2 \text { days } \\
\text { after the 1st dose }\end{array}$ & $\begin{array}{l}\mathrm{PSL}+ \\
\mathrm{IVIG}\end{array}$ & 2 days \\
\hline 2 & 61 & Female & 11 months & No & 132 & Pfizer & 1.0 & $\begin{array}{c}17 \text { days } \\
\text { after the } 2 \text { nd dose }\end{array}$ & $\begin{array}{l}\text { PSL + } \\
\text { EPAG }\end{array}$ & $11-25$ days \\
\hline 3 & 73 & Female & NA* & NA* & 230 & Moderna & $<1.0$ & $\begin{array}{l}11 \text { days } \\
\text { after the } 1 \text { st dose }\end{array}$ & $\begin{array}{l}\text { PSL + } \\
\text { IVIG + } \\
\text { EPAG }\end{array}$ & 8 days \\
\hline
\end{tabular}

*The patient had no history of ITP.

NA; not applicable

PSL; prednisolone, IVIG; intravenous immunoglobulin, EPAG; eltrombopag

Fig. 1 A Clinical course of case 1. B Clinical course of case 2. C Clinical course of case 3. D Summary of patient characteristics, clinical course, and treatment.

she was diagnosed with exacerbation of ITP. Drug-induced thrombocytopenia was ruled out based on her history. Platelet transfusion and oral PSL $25 \mathrm{mg} /$ day $(0.5 \mathrm{mg} / \mathrm{kg})$ was started immediately on the day of hospitalization. The platelet count remained low at $3 \times 10^{9} / \mathrm{L}$ on day 3 of hospitalization, and thus eltrombopag $12.5 \mathrm{mg} /$ day was started on day 5 (Fig. 1B). On day 7, the platelet count rose to $11 \times 10^{9} / \mathrm{L}$ and cutaneous purpura progressively improved. Platelet count increased further to $25 \times 10^{9} / \mathrm{L}$ on day 10 and $130 \times 10^{9} / \mathrm{L}$ on day 25 . 
Case 3 was a 73-year-old woman being followed for hypertension and hyperlipidemia who presented to our hospital with generalized petechiae. Eleven days before the hospital visit, she received the first dose of mRNA-1273 SARS-CoV-2 vaccine (Moderna) (Fig. 1C). She did not take any medication before or after vaccination. She had no history of autoimmune disease. Bleeding from the oral mucosa and petechiae on her face, body and both legs were observed on physical examination. Laboratory tests showed a platelet count of $2 \times 10^{9} / \mathrm{L}$ with normal PT-INR, APTT, fibrinogen, FDP and D-dimer. Bone marrow examination revealed normocellular marrow with normal number of megakaryocytes. Considering that the clinical and laboratory findings were consistent with ITP, oral PSL was started at $55 \mathrm{mg} /$ day (1 $\mathrm{mg} / \mathrm{kg}$ ) with IVIG $20 \mathrm{~g} /$ day for 5 days. However, platelet count further decreased to less than $1 \times 10^{9} / \mathrm{L}$ and bleeding symptoms had exacerbated on day 4 . In addition to purpura and petechiae on her skin, she began experiencing melena due to diffuse bleeding from the gastric mucosa. Therefore, eltrombopag $12.5 \mathrm{mg}$ was initiated on day 4 . On day 8 , platelet count increased to $96 \times 10^{9} / \mathrm{L}$ and bleeding symptoms started to improve. On day 11, platelet count further increased to $248 \times 10^{9} / \mathrm{L}$.

Kuter et al. have shown that the latency of developing thrombocytopenia or bleeding symptoms after vaccination was 2-5 days in most cases [2]. However, in our study, 2 patients developed severe thrombocytopenia after 11 and 17 days after receiving the last dose of vaccine (Fig. 1D), and another study also reported several cases who developed thrombocytopenia 2 weeks after vaccination [3]. Therefore, providers across the world should look out for bleeding tendency or thrombocytopenia for at least 2 weeks after SARSCoV-2 vaccination, even in patients with ITP in remission or healthy individuals, to avoid serious hemorrhagic consequences of severe thrombocytopenia. As for the treatment, all previously reported cases except one responded well to corticosteroids with or without IVIG, while a thrombopoietin receptor agonist, romiplostim, was used for one case. In our cases, two out of three required eltrombopag for effective platelet recovery (Fig. 1D), indicating that intensive treatment including a thrombopoietin receptor agonist may be required in some cases. We believe that rituximab would be the last option to consider, since rituximab strongly impairs antibody production after vaccination by eradicating B cells.

\section{Declarations}

Conflict of interest The authors declare that they have no conflict of interest.

\section{References}

1. Kupietzky A, Parnasa E, Fischer M, Kuint R, Daana M. Immune thrombocytopenia secondary to COVID-19 infection. Isr Med Assoc J. 2021;23:342-3.

2. Kuter DJ. Exacerbation of immune thrombocytopenia following COVID-19 vaccination. Br J Haematol. 2021. https://doi.org/10. 1111/bjh.17645.

3. Welsh KJ, Baumblatt J, Chege W, Goud R, Nair N. Thrombocytopenia including immune thrombocytopenia after receipt of mRNA COVID-19 vaccines reported to the vaccine adverse event reporting system (VAERS). Vaccine. 2021;39:3329-32.

Publisher's Note Springer Nature remains neutral with regard to jurisdictional claims in published maps and institutional affiliations. 